with PsA (23M, 6F; mean age $48.1 \pm 14.2 \mathrm{yrs})$ and nineteen with $\mathrm{OA}(9 \mathrm{M}, 10 \mathrm{~F}$; mean age $63.6 \pm 8.8 \mathrm{yrs})$. After centrifugation sera and $\mathrm{SF}$ were stored at $-20^{\circ} \mathrm{C}$ and a sandwich enzymelinked IL-18 immunoassay was performed. Statistical analysis was carried out using non parametric methods.

Results IL-18 levels were significantly higher in SF than in sera of either RA (mean value $\pm \mathrm{SD}=6,758 \pm 3,702 \mathrm{pg} / \mathrm{ml}$ vs 575 $\left.\pm 1,118 \mathrm{pg} / \mathrm{ml}, \mathrm{p}=<1 \times 10^{-6}\right)$, PsA $(4,234 \pm 2,834 \mathrm{pg} / \mathrm{ml}$ vs $\left.556 \pm 634 \mathrm{pg} / \mathrm{ml}, \mathrm{p}=<1 \times 10^{-5}\right)$ and OA patients $(1,054 \pm$ $1,215 \mathrm{pg} / \mathrm{ml}$ vs $283 \pm 542 \mathrm{pg} / \mathrm{ml}, \mathrm{p}=0,002)$. Serum IL-18 levels were significantly higher in $\mathrm{RA}(\mathrm{p}<0.05)$ and in PsA ( $\mathrm{p}<$ 0.01 ) than in OA, while no significant difference between RA and PsA serum levels was found. SF IL-18 levels were significantly more increased in RA than in PsA $(\mathrm{p}<0.01)$ and OA (p $<1 \times 10^{-8}$ ). SF IL-18 levels in PsA were also higher than in OA $(\mathrm{p}<0.0002)$.

Conclusion This study indicates that IL-18 levels are augmented in immune-mediated inflammatory arthropaties such as RA and PsA as against OA where degenerative mechanisms are generally associated with mild inflammation. The difference found is more striking if SF rather than sera were considered. The increased concentration of IL-18 found in SF as against sera in the three groups of patients suggests a pivotal role of this cytokine in local mechanisms of inflammation.

\section{THU0032 THE ASSOCIATION OF SERUM MATRIX METALLOPROTEINASES AND THEIR TISSUE INHIBITOR LEVELS WITH SCLERODERMA DISEASE SEVERITY}

A Kessel, E Toubi, G Grushko, E Sabo, M Rozenbaum, I Rosner. Division of Clinical Immunology and Rheumatology, Bnai-Zion Medical Center, Faculty of Medicine Technion, Haifa, Israel

\subsection{6/annrheumdis-2001.829}

Background Matrix metalloproteinase 3 (MMP-3) is reported to play an important role in the pathogenesis of Systemic Lupus Erythematosus (SLE) and Rheumatoid Arthritis (RA). Studies have also investigated the association of different tissue inhibitors of MMPs (TIMPs) with fibrosis in scleroderma (SSc).

Objectives To evaluate the correlation of serum MMP-1,3 and TIMP-1 with severity and disease specific markers of SSC and RA.

Methods Serum MMP-1,3 and TIMP-1 were measured in 42 SSc patients (age range 28-68 y, mean $47 \mathrm{y}$ ) and compared to measurement in 29 RA and healthy age/sex individuals. Elevated values of MMPs and TIMP-1 were defined as those greater than 2 S. D above normal mean. All SSc and RA patients were scored for disease severity.

Results Serum MMP-1 was significantly elevated in 8/42 (19\%) SSc patients $(\mathrm{p}=0.01)$ but only in $2 / 29(7 \%)$ RA patients $(\mathrm{p}=$ 0.2). Whereas MMP-3 levels were elevated in 10/29 (34\%) RA patients $(\mathrm{p}=0.002)$, it was elevated in only $5 / 42(12 \%)$ SSc patients (0.03). TIMP-1 was found elevated in 17/42 (40\%) SSc patients $(p=0.001)$ and in only 4/29 RA patients (a strong trend towards significance $p=0.052$ ). We found a significant association between the elevation of both MMPs and TIMP-1 levels, with the severity of SSc. Those who had an increase of more than one MMP and/or TIMP, demonstrated life-threatening major organ involvement such as severe lung fibrosis, diffuse GI, or kidney involvement and severe cardiac failure. Contrary to that in SSc, the severity of RA was associated with MMP-3 only.
Conclusion We confirm previous observations that MMPs and TIMPs may play an important role in various rheumatic diseases. Whereas serum increase of MMP-3 correlated with RA severity, SSc severity was characterised mainly by the increase of both MMP-1 and TIMP-1. This suggests that the MMPs and TIMPs involved in SSc are different than those playing a role in RA. These factors may play a synergistic role in the severity ofsystemic sclerosis.

\section{THU0033 THE CHEMOKINE MIP-1ALPHA IN RHEUMATOID ARTHRITIS - POSSIBLE SIGNIFICANCE ON INFLAMMATION AND ANAEMIA}

${ }^{1}$ WC Kullich, ${ }^{2} \mathrm{G}$ Pöllmann, ${ }^{2} \mathrm{H}$ Neff, ${ }^{1} \mathrm{G}$ Klein. ${ }^{1}$ Ludwig Boltzmann Institute for Rehabilitation of Internal Diseases; ${ }^{2}$ Rehabilitation Centre for Rheumatic Diseases, PVArb., Saalfelden, Austria

\subsection{6/annrheumdis-2001.830}

Background Chemokines play a key role in modulating leukocyte functions at sites of inflammation. In rheumatoid arthritis (RA) an enhancement of the chemokine macrophage inflammatory protein-1alpha (MIP-1a) was observed and may be indicative for inflammatory processes. ${ }^{1}$ In addition to its proinflammatory activities several lines of evidence indicate that MIP-1a modulates the proliferation of hematopoietic progenitor cells. $^{2}$

Anaemia is a common feature of active rheumatoid arthritis. Very little information on the significance of MIP-1a on the pathogenesis of anaemia in RA is available.

Objectives Basing on theoretical, haematological and immunological data, the chemokine MIP-1a was to be determined about its importance in RA concerning the activity of inflammation and the development of anaemia.

Methods 84 patients (18 male, 66 female) with rheumatoid arthritis (ACR criteria) were included to detect inflammatory processes and anaemia. White and red blood cell count, erythrocyte sedimentation rate (ESR), C-reactive protein (CRP), serum iron and the rheumatoid factor were assessed by routine laboratory methods. MIP-1a, serum amyloid A (SAA) and transferrin receptor (TfR) were measured by solid phase enzyme immunoassay; erythropoietin (EPO) and neopterin by radioimmunoassay techniques.

Results High MIP-1a levels were accompanied by increased parameters of inflammation (SAA, CRP, ESR). Patients with RA and anaemia showed significantly higher MIP-1a levels than those without anaemia $(\mathrm{p}<0.03)$. However, high MIP-1a levels together with decreased serum iron were not associated with increased EPO levels. It might be of importance that patients with high MIP-1a levels in parallel with anaemia and activation of inflammation had a twofold frequency of disability pension compared to RA patients without anaemia.

Conclusion The enhanced expression of MIP-1a in RA is indicative of the inflammatory activation. Moreover besides the regulation of inflammatory processes this chemokine may influence the pathogenesis of anaemia in RA.

\section{REFERENCES}

1 Koch AE, Kunkel SL, Harlow LA, et al. Macrophage inflammatory protein-1 alpha. A novel chemotactic cytokine for macrophages in rheumatoid arthritis. I Clin Invest. 1994;93: 921-8

2 Su SB, Mukaida N, Wang JB, Zhang Y, Takami A, Nakao S, Matsushima K. Inhibition of immature erythroid progenitor cell proliferation by macrophage inflammatory protein-1a by interacting mainly with a C-C chemokine receptor, CCR1. Blood 1997;90(2):605-11 